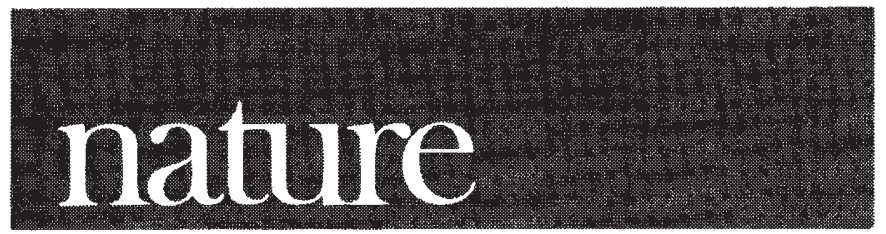

Volume 247

January 4,1974

\section{Government by stealth and secrecy}

BRITAIN is now confronted with a severe economic crisis, the ingredients of which are well known, and even when the miners, engine drivers and power station engineers return to full-time working there is bound to be a period of general inconvenience and little prospect of improvements in the standard of living for some time to come. Many things are bound to change as a result of the crisis and it is to be hoped that among them will be the style of government under which Britain has operated for a very long time-specifically the obsessive secrecy and stealth with which Whitehall works and the serious lack of information provided to the public.

This complaint is, of course, fashionable and it is equally fashionable to pay lip-service, as did $\mathrm{Mr}$ Heath in 1970, to 'open government'. The question is not whether Britain provides less information than other countries, although it palpably does in comparison with, say, the United States, but whether it provides enough information for those who wish to know, and who do not choose to work for the Civil Service, to be able to come to independent and balanced conclusions.

A conventional defence is to point to such institutions as Question Time in the House of Commons and a free press. This is a very shallow response. The character of Question Time is to find quick, witty and crushing responses to issues raised. This is a political process and success at this facile operation is deemed to be a prerequisite of a good politician. This highly prized skill with words, which spills over into all political exchange, does nothing but damage to a country which needs rational assessment. It is no accident that 'evaluation', a word used almost to excess in the United States, is relatively rare in Britain.

Can a free press make up for this deficiency? Journalists have to depend on a heterogeneous collection of sources for information, from leaks to plain inference. It is simply not possible always to guarantee that one man working against a system will be successful, and it would be foolish to expect more than honest effort. A free press is no replacement for free information and no journalist would regard an increase in the flow of facts as other than beneficial to his operations, certainly not as a threat to his profession.

During the energy crisis the government has operated sufficiently frequently by stealth and suppression of information to raise serious doubts that its style can be supported indefinitely by an electorate. After weeks of denying that the fuel shortage was serious enough to warrant strong corrective action, ration books are issued with such indecent haste that the As and Bs with coughs and colds have probably missed out. After
Post Offices close for the weekend nine days before Christmas an announcement is made that no further Christmas parcels will be accepted. After talking of still going for growth, in the full knowledge of fuel shortages, the government days later imposes a three-day working week and demolishes thoughts of growth.

This is rule by edict and secrecy and is not, it must be emphasised, restricted to the present government. Rather, the channels for advance warning, discussion and compromise fail to exist.

There is much talk at present of the appointment of an energy supremo in Britain, and several names have been mentioned. It is difficult to know whether the idea can be welcomed. If the supremo is a party politician dedicated to the present system of operation and only prepared to give political answers to questions, then the creation of another agency may profit the country not at all. If, on the other hand, someone can be found who will work honestly and openly and recognise the need for the public to receive facts and figures in support of decisions he will deserve wide support.

\section{0 years ago}



From Nature, 9, 184, January 8, 1874. 